\title{
THE IMPORTANCE OF DEVELOPING SECURITY CULTURE AMONG MILITARY PERSONNEL AS A WAY TO MITIGATE THE TERRORIST THREAT
}

\author{
Laurențiu- Leonard LĂZĂROIU \\ “Nicolae Bălcescu" Land Forces Academy Sibiu, Romania \\ Illazaroiu@yahoo.com
}

\begin{abstract}
A higher level of knowledge owned by military personnel about the specific actions of terrorist organizations, especially those used to recruit new members from colectivities of military personnel, in particulary military cadets, is a matter of novelty and requires some security education values in order to face the current threats.

In the last 5 years, the Internet has become the preferred vehicle for spreading the radical jihadist discourse and a recruitment field of followers, eager to be involved directly or indirectly through logistical support, financial information for terrorist purposes. The interest of terrorist organizations for the social category, represented by young soldiers or cadets, is given by their access to information and skills on weapons, ammunition, explosives usage and even the information about how and from where find and steal them. More than that it appears the intention of recruitment and cultivation a secret and confident relationship with the future military personnel to obtain classified information, especially about terrorist actions organized by the specialized antiterrorist structures of the state.
\end{abstract}

Keywords: security education, terrorist threat, persuasion, classified information, risky behaviour.

\section{Introduction}

In each organization the most valuable components are human resources, but also those are the most sensitive which is vulnerable to internal and external influences that can affect his own performance or the safety of the group to which those people belong. Illegal actions with serious implications for national security by engaging in terrorist activities or unauthorized dissemination of classified information for terrorist purposes is a risk posed by human factor, directly-the intention to commit this or indirectly-as a result of several external factors: procedural errors, organizational deficiencies, vulnerabilities in IT management. Whichever way we assess the issue, the most vulnerable part of the protection system it is usually proved to be human. All specific actions to develop security education have a role or knowledge of the human personality, characteristics of occupational categories, in order to reduce the negative effects of uncertainty and unpredictability of the human factor. All specific actions use for developing security education have also a second role, the knowledge of human personality and founding characteristics of occupational categories, in order to reduce the negative effects of uncertainty and unpredictability of the human factor.

The organizational integration of any new member is a part and a stage of social integration, it largely depends on learning the rules that structure the socioprofessional relations and also on the subjective capacity of behaviour's adaptation to situations where, even are 
defined very precise rules of action, there is sometimes a tendency to abuse them. Therefore, as social integration includes general permanently rules adapted to social context, as training and security culture development is a continuous process which began when selecting staff. This process occurs throughout the professional activity, with the permanent integration of knowledge and operational procedures to potentially dangerous challenges on classified information. Assuming theoretical training of people, according to organizations goals, even it is completed at the end of professional activity, security culture, by preserving similar principles throughout his career, will mark the individual's lifetime.

The obligations imposed by the social role, submitted by professional rules, are designed on social interactions plan in the form of expectations or what can be expected from the one who fulfil that role. The social role gives every individual the chance to correctly interpret the meaning of the actions that normally are done in a subjective and objective manner.

In an overview, by these two components: personnel selection and subsequent, by security education process, we understand the imposition of some conditions and a practical and theoretical assimilation of a certain social role, according to military environment. This role is not independent, but blended with other social roles, consistent adapted to one another, performed by the individual in the form of a continuous and mixed process. We appreciate that people do not behave mechanically, isolated for each social role, they don't act as robots that invariably react to comparable situations and whose behaviours are totally predictable and can be anticipated. In the fact the consistency or the inconsistency of obligations and expectations reveal either consensus or disagreement.

We believe that the interaction of social roles, even if the rejection of all the values of a role can be masked in the social manifestation, the action of the individual under another social role will reveal in a direct or veiled way the true perception and reaction to those values to which the person disagrees.

Some specialists from Defense Personnel Security Research Center allowed six active fields to be taken into consideration by the staff with responsibilities of management to minimize the risk from employees' behaviour, the first three are considered with a higher relevance in the selection process of candidates [1]:

a) practices and internal policies;

b) recruitment methods of personnel;

c) Screening of candidates on previous work (advice, assessments);

d) Preparing effective and specific security education;

e) Continuity evaluation and implementation of appropriate policies to current challenges;

f) Management intervention;

The roles that people learn to interpret (better or worse) constitute sets of definite rules, subjectively and objectively recognizable, through human behaviour can be understood and anticipated. Learning of these roles shall be carried out in a dynamic context, in which the social environments of the individual have permanent complicated their structures and also their interactions, thus making necessary the conventionalization of relations. We also consider that specific professional roles in the military field involves a constant strictness, also some certain behavioural rigidities, which have been overcome in other social roles performed by the individual in society.

\section{Increasement of terrorist threat across European young people}

By the dynamics increase of jihadist ideological offensive amongst young Europeans we identify a particular category of interest to terrorist organizations represented by students and more than that 
by military students. For a terrorist organization I consider the interest to this social category is given by the access of young soldiers to information and data on weapons, ammunition, explosives, the knowledge about its usage and even in formation about stealing them. More than that the intention of recruiting military personnel and growing relationship over time have a special goal to the terrorist organization in order to obtain information about terrorist actions organized by specialized state structures and appropriate disclosure of these. The information could be shares to a representative contact, a member of the terrorist organization.

According to the Centre de Prevention de Deradicalisation et Suivi Individuele (CPDSI) from France, in the period January-September 2016, French security forces identified 1954 young French supporters of the Islamic State (ISIS). Statistics said that the radicalization of youth increased by 121 percent over 2015 [3].

More than that, the French foreign Minister, Bernard Cazeneuve, said that the terrorist threat in France is more than ever, about 300 people were arrested in 2016 on suspicion that they supported with information and they committed actions with terrorist flavour. CPDSI report shows that over $90 \%$ of French citizen's recruitment to join the ideological jihad were made online. In 2015 and 2016 at least 17 young French died, fighting for ISIS in Syria and Iraq.

Terrorists have improved recruitment and indoctrination techniques so much as they offer customized models to address for a higher category of interest, especially among adolescents. To be as convincing, ISIS members have developed and have used for the persuasive purpose, in the recruitment process of new followers, five popular myths, designed and applied successfully to attract young supporters.

These models were called symbolic as follows [2]:
- The myth "knight hero" operating successfully for handling young male;

- The myth "humanitarian cause" to help children gassed by the Syrian government. Technology finds followers among the young female;

- The myth "call of duty", referring to the video game with the same name, uses the persuasion techniques for targeting young people who want to fight;

- The myth "the one that is bringing water" model that works for indoctrinating young people looking for a leader;

- Myth "unlimited" used successfully handling challenges and adrenaline seekers.

The French evaluation report emphasizes the fact that the extreme danger that radical jihadists is due to the use of the familiar universe, like references to the video game world. Virtual violence of a game like "Assassin's Creed" may determine a sensitive young man to leave his social environment and to move in conflict areas, controlled by terrorists, for a real encounter with specific scenarios games.

The fundamentalism can be found in all religions, it is often identified common characteristics. Fundamentalists play the lawyers role for a considered minority oppressed, even when numeric, they represent a great value. They oppose to secularisation and are led by charismatic leaders with great power of persuasion. Contemporary fundamentalism, even it is Christian, Jewish, Hindu, Islamic, is a reaction to traditional features of secular society, is interested in restoring a faithful society, paradoxically, with the help of: mass-media, bureaucratic institutions and even weapons of mass destruction.

Religious fundamentalism is a consequence of technological progress before whom people desperately cling to what is familiar, looking for simple answers to complex, discouraging situations.

These often simple and wellbeing responses, offered by fundamentalist 
doctrines, were accepted by believers as long as they do not take on their shoulders the burden of discernment and as long it guarantees the punishment of each real or perceived enemy.

\section{Applying the persuasive techniques by terrorist entities}

Expressed as an act of communication, the persuasion is intended to change the mind set of human target, differing from other forms of influence by two features:

- the target subject has the impression of a total freedom;

- the outcome is translated into behaviour modification, gaining consent and internalization of this agreement.

Generally, individuals have a strong sense of subjective immunity, often registering a tendency to minimize the likelihood of negative consequences of everyday tasks. But when tasks and actions, accepted by the human subject to be performed, should be condemned by organization to which subject belongs, knowing some further consequences causes a state of psychological tension.

From the perspective of individual introspection, when drawing intention of committing reprehensible socioprofessional actions, an interesting element becomes the relationship between perception of risk exposure and the real choices. Inevitably there will appear questions like: What are the consequences of accepting a risk? Benefits of a behavior are higher than energy consumption used to find a proper risk management?

In terms of counterintelligence structures, whose defensive role in protection of classified information is a normal task, a question will arise: Under what conditions individuals assume a conscious risk and under what conditions they prefer to choose a non-hazardous behaviour or some preventive measures?

If in socio-psychological research the risk can be rigorously analyzed and understood in all manifestations, in everyday life it is unlikely that individual to use scientific calculations for performing and developing actionable decisions.

Therefore, the behaviour under risky circumstances is the result of estimates, made stereotypical, depending on schemes formed over time or on the case law and examples of subject experience in taking duplicitous behaviours, reprehensible professional.

In the process of changing their values, the initiating agent of persuasive action has as a second aim, beyond changing attitudes and acceptance of a new behaviour, creating the illusion of control, development of selfconfidence (for the target subject) outlining the illusion that the acceptance of cooperation it will have a great benefit. For the one interested in accepting a conformist attitude of the correspondent (the target subject) it would be absurd and unrealistic only the presentation of benefits, regardless of the risk of failure. The balance resulting from a relatively objective analysis will be in favour of accepting the new behaviour. Those negative elements, disadvantageous for individual, will be masked and seemingly annihilated by accepting a discrete behaviour based on a conspiracy relationship. This creates a double persuasion, which guarantees a time continuity of relationship between individuals in terms imposed by persuasive agent.

Individual risks assumed are part of human nature, it is and will always be a modus vivendi for people and society in general. This modus vivendi is subject to risk awareness, a modus cognoscendi where taking an action is determined by a rational thought.

\section{Conclusions}

More than ever the Islamic ideology of fundamentalism stems beyond the religious context, from the contact with Western ideology, addressing the same category of individuals who were attracted earlier in history to communism and fascism. 
Accepting this idea as valid we extract a new conclusion that is relative to current realities. Thus, if the twentieth century was marked by the burden of the Cold War, the twenty-first century is influenced by Islamic extremism terrorism. Like communism, dominated by fascist and nationalist storms, started during the Cold War, terrorism will recruit the most loyal and conscientious followers from the people who lives in capitalist states. The recruitment process will be based on intrinsic motivation, main oriented by the attraction's value, acceptance of new concepts, totally different from those promoted by capitalist society. Concepts, born from extremist ideology, will be interpreted by some members of specific segments of society as been opposed to superficial values of democratic countries and to the monotony of modern society, marked by globalization. Thus, using partly psychological procedures with the eccentric and exclusive character, promoted by extremists recruiters by presenting some glorious aspects even they are condemned by social norms, will fuel young people desire to stand out, they will be relatively easily directed to action in a certain way that will represent a real risk to national security. The contemporary reality has shown that as the Internet becomes the primary way of radicalization, passing through the mosque is no longer automatic, ideological texts are designed to be the best weapon of online persuasive actions.

To sum up, more than gathering classified information from young military personnel who has access to them, using special procedures of ideological indoctrination, the recruitment of human sources will have the main goal the participation and in terrorist attack by selecting well trained military people.

\section{References}

[1] Eric.D.Show, Lynn F.Fischer, Insider risk evaluation and audit tools, Defense Personnel Security Research Center, PERSEREC Report, aug.2009, http://www.dhra.mil/perserec/reports/pp09-03.pdf, accesed on 06.12.2015..

[2] Dounia Bouzar, Comment evaluer un ebrigadement djihadiste, 2016, disponibil la http://www.cpdsi.fr/radicalisation/, accessed on 12.10.2016

[3] Ibidem. 